\title{
Does sharing leadership actually work? An evaluation of the benefits and drawbacks of shared leadership
}

\author{
Nathaniel Herbst ${ }^{1}$ \\ Carlos Rios-Collazo ${ }^{2}$ \\ Jesse Denison ${ }^{3}$
}

\begin{abstract}
Shared leadership is being utilized in increasing measures across a spectrum of organizations. It appears to afford numerous advantages within the context of the evolving modern workforce. Most of the studies on shared leadership have focused on its benefits, but few have considered potential weaknesses. This research sought to ascertain whether the benefits that have been correlated with this leadership model are valid and what drawbacks and limitations might be associated with it. This was accomplished by surveying prominent leaders from several faith-based organizations in the United States that utilize shared leadership. Thirteen leaders from 7 organizations were interviewed. An emergent design and a qualitative approach were employed, along with a purposive sampling technique. A descriptive approach based on semi-structured interviews was adopted to help elucidate the benefits and drawbacks these groups encountered. Ten benefits that were found in the academic literature had also been observed in the organizations surveyed. These included exceptional outcomes, enhanced decision-making, complex problem solving, creative innovation, team-member fit, team synergy, organizational vitality, healthy organizational culture, individual wellbeing, and sustained growth. Five drawbacks were also discovered. These included the difficulty of the model, a potential lack of follow-through, a possible lack of efficiency, a general lack of acceptance of the model, and the danger of immature or usurping team members. The description of these five limitations is a novel contribution to this field of inquiry.
\end{abstract}

Keywords: Leadership, Shared leadership, Collaborative decision-making, Team leadership, and Decentralized leadership

\section{Introduction}

There has been significant interest in the topic of shared leadership in recent years. A growing body of research has accompanied this (Barnett \& Weidenfeller, 2016). Much of the research on shared leadership has noted its benefits. The accompanying literature review will provide a sampling of that

\footnotetext{
${ }^{1}$ Nathaniel Herbst, Ph.D., Team Coordinator, Great Commission Alliance, USA

${ }^{2}$ Carlos Rios-Collazo, Ph.D., Professorial Lecturer, Monroe College, USA

${ }^{3}$ Jesse Denison, Graduate Student, Denver Seminary, CO, USA
}

https://doi.org/10.34097/jeicom_1_1_3 
material. Potential drawbacks associated with the model have received far less attention. This study was designed to evaluate both benefits and limitations.

\section{Literature Review}

Shared leadership can be defined as distributed leadership on a team (Carson, Tesluk, \& Marrone, 2007; Ensley, Hmieleski, \& Pearce, 2006; Pearce \& Sims, 2002) and collective influence within a team (Sivasubramaniam, Murry, Avolio, \& Jung, 2002). It "entails a simultaneous, ongoing, mutual influence process within a team" (Pearce, 2004, p. 48). This paper will use the term shared leadership in a general way that refers to the distribution of leadership and influence on a team rather than a specific organizational structure.

There has been an emerging trend away from the top-down leadership models of the past and towards collective approaches (Friedrich, Griffith, \& Mumford, 2016). Serban and Roberts (2016) note, "Leadership research, traditionally focused on the behavior of an appointed/elected leader, is rapidly shifting towards a distributed, group process form of leadership known as "shared leadership"' (p. 181). The focus on shared forms of leadership has been increasing steadily (Friedrich et al., 2016).

Many benefits with this model have been observed and were previously categorized under the following ten groupings (Herbst, 2017). These include exceptional outcomes, enhanced decision-making, complex problem solving, creative innovation, team-member fit, team synergy, organizational vitality, healthy organizational culture, individual wellbeing, and sustained growth.

Shared leadership has been associated with exceptional outcomes, such as team success (Shipper, Manz, Nobles, \& Manz, 2014), improvements in performance (Carson et al., 2007; Daspit, Ramachandran, \& D’Souza, 2014; D’Innocenzo, Mathieu, \& Kukenberger, 2014; Sivasubramaniam et al., 2002), motivational and cognitive advantages (Solansky, 2008), leadership behavior and efficiency (Bergman, Rentsch, Small, Davenport, \& Bergman, 2012), effectiveness (Daspit, Tillman, Boyd, \& Mckee, 2013; Haward, Amir, Borrill, Dawson, Scully, West, \& Sainsbury, 2003; Hiller, Day, \& Vance, 2006; Wang et al., 2014), proactivity and productivity (Erkutlu, 2012; Olivia \& Shao, 1996), quality and service (Olivia \& Shao, 1996; Manz, Skaggs, Pearce, \& Wassenaar, 2015; Perry, 2000), and exponential growth (Hesselbein \& Goldsmith, 2009). These benefits are more frequently observed in knowledge and information related work (Fausing, Jeppesen, Jønsson, Lewandowski, \& Bligh, 2013).

Enhanced decision-making can be another benefit of shared leadership. Distributed decision-making can be advantageous (Petrovia \& Hristov, 2016). Information and knowledge sharing can help teams make better decisions (Brodbeck, Kerschreiter, Mojisch, \& Schulz-Hardt, 2007; Supovitz \& Tognatta, 2013). While increased bureaucracy will often impair decision-making, empowering team-members may cultivate positive change and advancement (Hamel \& Zanini, 2017). The benefits of collaborative decision-making require information sharing (Panahifar, Heavey, Byrne, \& Fazlollahtabar, 2015) and a diversity of team members that are proficient in communication (Deng, Lin, Zhao, \& Wang, 2015). A team's ability to share, evaluate, and process information has been reported as a critical factor affecting the quality of collaborative decision-making (McLeod, 2013).

Complex problem solving is another advantage associated with shared leadership. While the benefit is related to decision-making, it also entails information sharing. Problem-solving in complex and challenging situations requires knowledge sharing, a key feature of shared leadership (Clarke, 2012; Han, Lee, Beyerlein, \& Kolb, 2018). Knowledge sharing is related to creative problem solving (Carmeli, 
Gelbard, \& Reiter- Palmon, 2013). Wang, Waldman, \& Zhen (2014) write, "the effects of shared leadership are stronger when the work of team members is more complex" (p. 181). When decisions must be made regarding the use of limited resources, "egalitarian" teams have functioned better than hierarchical teams, with reduced conflict and greater team unity (van Bunderen, Greer, \& van Knippenberg, 2018).

Creative innovation has also been associated with shared leadership (Nurmi, 1996). Shared leadership can lead to increases in creativity (Pearce, 2007; Pearce \& Conger, 2003; Mohammed \& Thomas, 2014; Oswald, 2018) and a "high level of administrative creativity" (Alanezi, 2016, p. 50). Hierarchical constraints can limit information sharing, creativity, and innovation, while teams that collaborate in relational ways can thrive (Tzabbar \& Vestal, 2015). Information sharing can lead to significant increases in creativity (Lee, Lee, \& Seo, 2011; Lee, Lee, Seo, \& Choi, 2015). Shared leadership also fosters innovation (Bligh, Pearce, \& Kohles, 2006; Shipper et al., 2014; Hoch, 2013), and it can even do so in a way that increases with task complexity (Hui-ying \& Jian-peng, 2013). As with previous benefits, information sharing is instrumental to experiencing these benefits of shared leadership (Jiang, Gu, \& Wang, 2015).

Team-member fit, a term that describes a team member's satisfaction, involvement, and commitment levels, is another outcome of shared leadership. Job satisfaction has been related to shared leadership (Hansen \& Høst, 2012; Steinert, Goebel, \& Rieger, 2006; Woods \& Weasmer, 2002). That can lead to ownership, participation, and involvement (Bamford-Wade \& Moss, 2010; Moe, Dingsøyr, \& Kvangardsnes, 2009). The benefits mentioned above can engender team-member commitment (Devos, Tuytens, \& Hulpia, 2014; Lee- Davies et al., 2007) and retention (Kleinman, 2004).

Shared leadership can also improve team synergy (Somboonpakorn \& Kantabutra, 2014) and has been associated with increased team performance (Carson et al., 2007) and effectiveness (Wang et al., 2014). Teams experience this as a consequence of increased trust (Drescher, Welpe, Korsgaard, Picot, \& Wigand, 2014). Shared leadership also fosters team coherence (Mathieu, Kukenberger, D'Innocenzo, \& Reilly, 2015) and can improve team accountability (Bamford-Wade \& Moss, 2010).

Organizational vitality is also related to shared leadership. Shared leadership helps organizations utilize their team members' strengths, abilities, and leadership potential (Miles \& Watkins, 2007). Distributing leadership can also help them make the best use of all the talent that exists across their staff (Lee-Davies, Kakabadse, \& Kakabadse, 2007). This can be better achieved on shared leadership teams since these teams distribute the expertise needed for organizational success across a broader array of qualified leaders (Spillane, Halverson, \& Diamond, 2004).

Organizational culture is something that evolves from the leadership of an organization (Schein, 2009). Shared leadership, like any other type of leadership model, has the potential to uniquely impact the organizational culture in which it operates. Indeed, this leadership model is related to knowledge sharing cultures (Taylor, 2013), and cultures of inquiry and collegiality in school settings (Khourey-Bowers, Dinko, Hart, 2005). Shared leadership can also foster cultures of organizational adaptability (Laloux, 2014). Adaptable cultures can also accommodate positive organizational change, something evident in shared leadership (Park \& Kwon, 2013). Shared leadership can also help facilitate organizational sustainability (Pearce et al., 2013).

Individual wellbeing has also been associated with shared leadership. As previously noted, shared leadership can improve job satisfaction, participation, involvement, commitment, and retention. One 
study even found that it can lead to reduced role confusion, role overload, role conflict, and job stress (Wood \& Fields, 2007). Shared leadership can also lead to fitness benefits, healthful regeneration, increased engagement, and stress management (Lovelace, Manz, \& Alves, 2007).

Sustained growth is another benefit of shared leadership. Pearce, Manz, and Akanno (2013) surmised, "decentralized, shared leadership was a better predictor of firm growth rates than centralized, vertical leadership" (p. 250). Malburg (1997) described "explosive growth" as a typical feature of "flat organizational structures" (p. 67). David Thompson explained that sharing leadership between codirectors with different but complementary strengths was a common feature of billion-dollar enterprises (as cited in Hesselbein \& Goldsmith, 2009). Marcus Buckingham (2005) has also noted how this has been typical in many successful technology companies (p. 274).

\section{Theoretical Framework}

Although the academic literature on this topic was full of research that supported the benefits of shared leadership, there was a conspicuous absence of research on its drawbacks. This project attempted to investigate the benefits mentioned above and probe for possible limitations.

\section{Methodology}

This qualitative investigation employed a descriptive approach, which utilized semi-structured interviews. This allowed for a better understanding of the antecedents and outcomes of shared leadership in Christian organizations, a sector that has not received adequate attention in this field. Shared leadership is a model of leadership that can be found in the Christian New Testament (Hellerman, 2013; Strauch, 2003). A significant number of Christian churches and organizations are embracing this type of leadership, but there have only been a small number of studies on shared leadership in this arena. There has also been minimal research concerning the drawbacks of shared leadership. For these reasons, the focus of this research was centered on Christian ministries utilizing shared leadership. A strategy of emergent design was employed. Purposive sampling led to the selection of 13 leaders from seven evangelical organizations in the United States that utilize shared leadership. The participants' data have been kept anonymous to minimize bias and ensure accuracy. The following four questions provided the foundation for the semi-structured interviews.

Question 1: Which benefits associated with shared leadership have you observed in your organization?

Question 2: What impact has shared leadership had on your organization (include quantifiable outcomes like innovative solutions, organizational growth, etc., and climate outcomes like work environment, relationships, etc.)?

Question 3: What impact has shared leadership had on you (personal growth, job satisfaction, organizational commitment, motivation, etc.)?

Question 4: What negative outcomes associated with shared leadership have you observed in your organization?

\section{Data Analysis}


Three interviews were conducted in person, and ten were administered by phone. All interviews were consensually recorded. Transcription was done with Trint software. Analysis was completed with MaxQDA-12 qualitative data analysis software.

\section{Results of the Study}

All of the participants had observed enhanced decision-making, complex problem solving, team-member fit, team synergy, and organizational vitality. A total of $92.3 \%$ of the leaders surveyed affirmed their experience of exceptional outcomes. Two respondents mentioned that this was true, but that the term "exceptional outcomes" could be interpreted in different ways. Similarly, 92.3\% of the participants reported creative innovation, with one respondent mentioning that the term could be interpreted in different ways as well. A total of $84.6 \%$ of the participants had observed healthy organizational culture, individual wellbeing, and sustained growth. Concerning sustained growth, 4 leaders were careful to mention that growth could be interpreted in different ways. Some of those surveyed experienced numerical growth while others perceived this benefit in other legitimate capacities. Table 1 below provides a summary of these data.

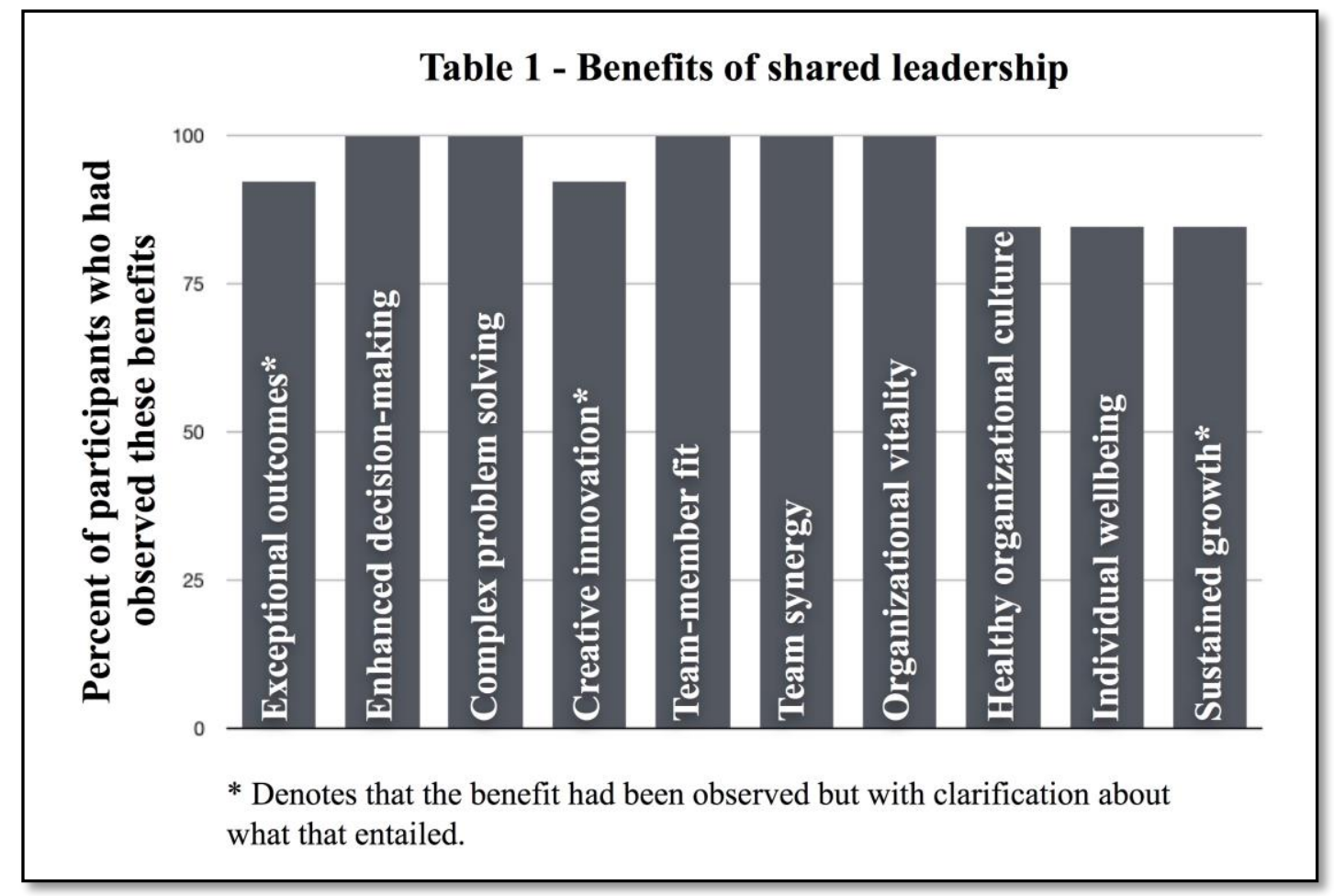

The potential drawbacks of shared leadership also needed to be considered, since there has been far less attention given to these in the academic literature. The leaders interviewed were queried on this subject as well. In this case, five potential drawbacks surfaced. These included the difficulty of the model, a potential lack of follow-through, a possible lack of efficiency, a general lack of acceptance of the model, and the danger of immature or usurping team members. More attention will be given to each below. One drawback that became evident was the inherent difficulty of the shared leadership model. One of the respondents stated that sharing leadership is the hardest way to do leadership but clarified that it is also the best way to do leadership. Another participant explained the difficulty his team had experienced in learning how to lead collaboratively. The structure that had evolved on their team was somewhat 
complex and had not come easy to them. Although these leaders believed in the model and had experienced success with it, they were also aware that making shared leadership work took time and effort.

Another problem some of those interviewed had encountered was the possibility for a lack of followthrough. One leader described this weakness, calling it an "organizational sand trap." He added, "In every form of governance there is going to be weaknesses. In this one, it can be easy to hide behind one another, procrastinate." He noted the need for accountability. Many agreed with that conclusion. One articulated that this way, "Absent of a real written, mutually agreed upon accountability culture, there is a great possibility that because everyone owns something nobody owns it and nothing gets done." Several participants shared similar concerns and emphasized the importance of accountability.

Another drawback that was reported was the potential for a lack of efficiency. One leader summarized this risk admitting that his team had at times gone "round and round on certain things" in a way that could be described as "anti-productive." Although many of those surveyed realized the risk of a lack of efficiency, they also noted that efficiency was not always the only consideration. In the context of education, Williamson and Blackburn (2019) noted, "When it comes to time, leaders have to weigh the slower decision process against the benefits that come from setting aside time for discussion and analysis of alternatives" (Williamson \& Blackburn, 2019, pp. 22-23).

Another difficulty that surfaced was the general lack of acceptance of the model, in the public and even among followers. Some of those surveyed pointed to the status quo of hierarchy and top-down leadership, and the way these traditional styles had conditioned people to think about leadership. Many people, familiar only with a hierarchal approach, can have a hard time accepting a shared model. Concerning shared leadership, one leader noted that some people "just cannot embrace it. It is too much for them. It is just too foreign for them. It does not make sense to them. It is a culture clash." Another agreed, saying that for most people, "This is a very foreign kind of thing." Related to this general lack of acceptance is the finding that those with existing high distinctions within an organization tend to be the most resistant to adapting to shared leadership models. This was corroborated in a study of physicians within the Veterans Health Administration (Stewart, Astrove, Reeves, Crawford, \& Solimeo, 2017).

A final risk that several participants noted with this model is the danger of immature or usurping team members. This drawback surfaced more than any other. This risk is also one that had been hinted at in the academic literature. Timperley (2005) warned of the danger of a "distribution of incompetence" in shared leadership (p. 417). One leader described this pitfall stating, "It is important not to have divisive people in there, though because divisive people can ruin the whole party really quickly." Another added, "I suppose it could be a disaster if you got a bunch of people on the board that just want to argue with each other." The leaders that highlighted this risk were adamant that teams had to get to a place of maturity, trust, and relational strength to be able to circumvent this obstacle.

\section{Conclusions}

The present study classified many of the benefits of shared leadership that have been found in the academic literature under ten specific categories. These included exceptional outcomes, enhanced decision-making, complex problem solving, creative innovation, team-member fit, team synergy, organizational vitality, healthy organizational culture, individual wellbeing, and sustained growth. The leaders interviewed in this investigation affirmed these outcomes in their organizations. These same 
leaders also highlighted five potential drawbacks. These included the difficulty of the model, a potential lack of follow-through, a possible lack of efficiency, a general lack of acceptance of the model, and the danger of immature or usurping team members.

Future research should further investigate the five drawbacks this study uncovered. It would also be essential to expand on this investigation by considering other potential pitfalls to this model of leadership. This survey only interviewed leaders from shared leadership teams that were committed to this model and experiencing success with it. Future research might investigate attributes that have led to the failure of teams utilizing this model that did not succeed.

This investigation confirmed many of the benefits that have previously been associated with shared leadership. It also uncovered five potential drawbacks. It seems evident that experiencing the positive outcomes of shared leadership requires the ability to navigate past its drawbacks. Shared leadership really does work but, like most things, it works best when done correctly.

\section{Acknowledgments}

Alexander Strauch, Larry Osborne, and Joseph Hellerman were instrumental in designing and coordinating many of the details of this project. Brent Powell, Jon Thaddeus Harless, and Howard Owens were also extremely helpful in the dissertation phase of this research.

\section{References}

Alanezi, A. (2016). The relationship between shared leadership and administrative creativity in Kuwaiti schools. Management in Education, 30 (2), 50-56.

Bamford-Wade, A., \& Moss, C. (2010). Transformational leadership and shared governance: An action study. Journal of Nursing Management, 18 (7), 816-822.

Barnett, R., C., \& Weidenfeller, N., K. (2016). Shared leadership and team performance. Advances in Developing Human Resources, 18 (3), 334-351.

Bergman, J., Z., Rentsch, J., R., Small, E., E., Davenport, S., W., \& Bergman, S., M. (2012). The shared leadership process in decision-making teams. The Journal of Social Psychology, 125 (1), $17-42$.

Bligh, M., C., Pearce, C., L., \& Kohles, J., C. (2006). The importance of self and shared leadership in team based knowledge work: A meso-level model of leadership dynamics. Journal of Managerial Psychology, 21 (4), 296-318.

Brodbeck, F., C., Kerschreiter, R., Mojisch, A., \& Schulz-Hardt, S. (2007). Group decision making under conditions of distribute knowledge: The information asymmetries model. Academy of Management Review, 32 (2), 459-479.

Buckingham, M. (2005). The one thing you need to know: ... About great managing, great leading, and sustained individual success. New York, New York: Free Press.

Carmeli, A., Gelbard, R., \& Reiter-Palmon, R. (2013). Leadership, creative problem-solving capacity, and creative performance: The importance of knowledge sharing. Human Resource Management, 52 (1), 95-121.

Carson, J. B., Tesluk, P. E., \& Marrone, J. A. (2007). Shared leadership in teams: An investigation of antecedent conditions and performance. Academy of Management Journal, 50 (5), 1217-1234. 
Clarke, N. (2012). Shared leadership in projects: A matter of substance over style. Team Performance Management, 18 (3/4), 196-209.

Daspit, J., J., Ramachandran, I., \& D’Souza, D., E. (2014). TMT shared leadership and firm performance: Investigating the mediating role of absorptive capacity. Journal of Managerial Issues, 26 (3), 219-239.

Daspit, J., Tillman, C., J., Boyd, N., G., \& McKee, V. (2013). Cross-functional team effectiveness. Team Performance Management, 19 (1/2), 34-56.

Deng, Z., Lin, Y., Zhao, M., \& Wang, S. (2015). Collaborative planning in the new media age: The Dafo Temple controversy, China. Cities, 45, 41-50.

Devos, G., Tuytens, M., \& Hulpia H. (2014). Teachers' organizational commitment: Examining the mediating effects of distributed leadership. American Journal of Education, 120 (2), 205-231.

D’Innocenzo, L., Mathieu, J., E., \& Kukenberger, M., R. (2014). A Meta-Analysis of Different Forms of Shared Leadership-Team Performance Relations. Journal of Management, 20 (10), 1-28.

Drescher, M., A., Welpe, I., M., Korsgaard, M., A., Picot, A., \& Wigand, R., T. (2014). The dynamics of shared leadership: Building trust and enhancing performance. Journal of Applied Psychology, 99 (5), 771-783.

Ensley, M. D., Hmieleski, K. M., \& Pearce, C. L. (2006). The importance of vertical and shared leadership within new venture top management teams: Implications for the performance of startups. Leadership Quarterly, 17 (3), 217-231.

Erkutlu, H. (2012). The impact of organizational culture on the relationship between shared leadership and team proactivity. Team Performance Management, 18 (1/2), 102-119.

Fausing, S., M., Jeppesen, J., H., Jønsson, S., T., Lewandowski, J., \& Bligh, C., M. (2013). Moderators of shared leadership: Work function and team autonomy. Team Performance Management, 19 (5/6), 244-262.

Friedrich, T., L., Griffith, J., A., \& Mumford, M., D. (2016). Collective leadership behaviors:

Evaluating the leader, team network, and problem situation characteristics that influence their use. Leadership Quarterly, 27 (2), 312-333.

Hamel, G., \& Zanini, M. (2017). What We Learned About Bureaucracy from 7,000 HBR Readers. Harvard Business Review Digital Articles, 2-8.

Han, S. J., Lee, Y., Beyerlein, M., \& Kolb, J. (2018). Shared leadership in teams. Team Performance Management, 24(3/4), 150-168.

Hansen, J., R., \& Høst, V. (2012). Understanding the relationships between decentralized organizational decision structure, job context, and job satisfaction-A survey of Danish public managers. Review of Public Personnel Administration, 32 (3), 288-308.

Haward, R., Amir, Z., Borrill, C., Dawson, J., Scully, J., West, M., \& Sainsbury, R. (2003). Breast cancer teams: The impact of constitution, new cancer workload, and methods of operation on their effectiveness. British Journal of Cancer, 89 (1), 15-22.

Hellerman, J. (2013). Embracing Shared Ministry: Power and Status in the Early Church and Why It Matters Today. Grand Rapids, Michigan: Kregel Publications.

Herbst, N., J. (2017). Leader-Leader Exchange in Shared Leadership Teams: An Investigation of Collaborative Harmony Among Co-Leaders in Christian Ministry. (Doctoral Dissertation). Retrieved from Piedmont International University Library. 
Hesselbein, F., \& Goldsmith, M. (2009). The Organization of the Future 2: Visions, Strategies, and Insights on Managing in a New Era. San Francisco, California: Jossey-Bass.

Hiller, N., J., Day, D., V., \& Vance, R., J. (2006). Collective enactment of leadership roles and team effectiveness: A field study. The Leadership Quarterly, 17 (4), 387-397.

Hoch, J. (2013). Shared leadership and innovation: The role of vertical leadership and employee integrity. Journal of Business and Psychology, 28 (2), 159-174.

Hui-ying, M., \& Jian-peng, W. (2013). The impact of shared leadership on innovation performance. Institute of Electrical and Electronics Engineers, July 17-19, 2013. 2013 International Conference on Management Science and Engineering (20th). 1385-1390.

Jiang, W., Gu, Q., \& Wang, G. (2015). To guide or to divide: The dual-side effects of transformational leadership on team innovation. Journal of Business and Psychology, 30 (4), 677-691.

Khourey-Bowers, C., Dinko, R., L., Hart, R., G. (2005). Influence of a shared leadership model in creating a school culture of inquiry and collegiality. Journal of Research in Science Teaching, $42(1), 3-24$.

Kleinman, C., S. (2004). Leadership: A key strategy in staff nurse retention. Journal of Continuing Education in Nursing, 35 (3), 128-132.

Laloux, F. (2014). Reinventing Organizations. Brussels, Belgium: Nelson Parker.

Lee-Davies, L., Kakabadse, N., K., \& Kakabadse, A. (2007). Shared leadership: Leading through polylogue. Business Strategy Series, 8 (4), 246-253.

Lee, K., C., Lee, D., S., \& Seo, Y., W. (2011). Proceedings of the 5th International Conference on Ubiquitous Information Management and Communication: Effects of shared leadership on team creativity through knowledge sharing in an e-learning environment. New York, New York: Association for Computing Machinery.

Lee, D., Lee, K., Seo, Y., \& Choi, D. (2015). An analysis of shared leadership, diversity, and team creativity in an e-learning environment. Computers in Human Behavior, 42, 47-56.

Lovelace, K., J., Manz, C., C., \& Alves, J., C. (2007). Work stress and leadership development: The role of self-leadership, shared leadership, physical fitness and flow in managing demands and increasing job control. Human Resource Management Review, 17 (4), 374-387.

Malburg, C. (1997). Surviving explosive growth. Journal of Accountancy, 184 (6), 67-72.

Manz, C., Skaggs, B., Pearce, C., \& Wassenaar, C. (2015). Serving one another: Are shared and selfleadership the keys to service sustainability? Journal of Organizational Behavior, 36 (4), 607 612.

Mathieu, J., E., Kukenberger, M., R., D’Innocenzo, L., \& Reilly, G. (2015). Modeling reciprocal team cohesion-performance relationships, as impacted by shared leadership and members' competence. Journal of Applied Psychology, 100 (3), 713-734.

McLeod, P., L. (2013). Distributed people and distributed information: Vigilant decision-making in virtual teams. Small Group Research, 44 (6), 627-657.

Miles, S., A., \& Watkins, M., D. (2007). The leadership team: Complementary strengths or conflicting agendas? Harvard Business Review, 85 (4), 90-98.

Moe, N., B., Dingsøyr, T., \& Kvangardsnes, Ø., (2009). Proceedings of the 42nd Hawaii International Conference on Systems Sciences: Understanding shared leadership in agile development: A case study. Honolulu, Hawaii: Shidler College of Business. 
Mohammed, M., \& Thomas, K. (2014). Enabling community and trust: Shared leadership for collective creativity. Foundation Review, 6 (4), 96-105.

Nurmi, R. (1996). Teamwork and team leadership. Team Performance Management, 2 (1), 9-13.

Olivia, Y., \& Shao, E., Y. (1996). Shared leadership in self-managed teams: A competing values approach. Total Quality Management, 7 (5), 521-534.

Oswald, J. (2018). Why we should embrace anarchy in the workplace. Management Today, 2.

Panahifar, F., Heavey, C., Byrne, P. J., \& Fazlollahtabar, H. (2015). A framework for collaborative planning, forecasting and replenishment (CPFR). Journal of Enterprise Information Management, 28 (6), 838-871.

Park, J., G., \& Kwon, B. (2013). Literature Review on Shared Leadership in Teams. Journal of Leadership, Accountability \& Ethics, 10 (3), 28-36.

Pearce, C. L. (2004). The future of leadership: Combining vertical and shared leadership to transform knowledge work. Academy of Management Executive, 18 (1), 47-57.

Pearce, C., L. (2007). The future of leadership development: The importance of identity, multi-level approaches, self-leadership, physical fitness, shared leadership, networking, creativity, emotions, spirituality and on-boarding Processes. Human Resource Management Review, 17 (4), 355-359.

Pearce, C., L. \& Conger, J., A. (2003). Shared leadership: Reframing the hows and whys of leadership. Thousand Oaks, California: Sage Publications.

Pearce, L., C., Manz, C., C., \& Akanno, S. (2013). Searching for the holy grail of management development and sustainability: Is shared leadership development the answer? Journal of Management Development, 32 (3), 247-257.

Pearce, C. L., \& Sims, H. P. (2002). Vertical versus shared leadership as predictors of the effectiveness of change management teams: An examination of aversive, directive, transactional, transformational, and empowering leader behaviors. Group Dynamics: Theory Research and Practice, 6 (2), 172-197.

Perry, J. (2000). Multidisciplinary shared leadership. Journal for Healthcare Quality, 22 (3), 18-21.

Petrovia, P., \& Hristov, D. (2016). Collaborative management and planning of urban heritage tourism: Public sector perspective. International Journal of Tourism Research, 18 (1), 1-9.

Schein, E., H. (2009). The Corporate Culture Survival Guide. San Francisco, California: Jossey-Bass.

Serban, A., \& Roberts, A., J., B. (2016). Exploring antecedents and outcomes of shared leadership in a creative context: A mixed-methods approach. Leadership Quarterly, 27 (2), 181-199.

Shipper, F., Manz, C., C., Nobles, B., \& Manz, K., P. (2014). Shared entrepreneurship: toward an empowering, ethical, dynamic, and freedom-based process of collaborative innovation.

Organization Management Journal, 11 (3), 133-146.

Sivasubramaniam, N., Murry, W. D., Avolio, B. J., \& Jung, D. I. (2002). A longitudinal model of the effects of team leadership and group potency on group performance. Group \& Organization Management, 27 (1), 66-96.

Solansky, S., T. (2008). Leadership style and team processes in self-managed teams. Journal of Leadership \& Organizational Studies, 14 (4), 332-341. 
Somboonpakorn, A., \& Kantabutra, S. (2014). Shared leadership and shared vision as predictors for team learning process, synergy and effectiveness in healthcare industry. International Journal of Innovation and Learning, 16 (4), 384-416.

Spillane, J. P., Halverson, R., \& Diamond, J. B. (2004). Towards a theory of leadership practice: A distributed perspective. Journal of Curriculum Studies, 36 (1), 3-34.

Steinert, T., Goebel, R., \& Rieger, W. (2006). A nurse-physician co-leadership model in psychiatric hospitals: Results of a survey among leading staff members in three sites. International Journal of Mental Health Nursing, 15 (4), 251-258.

Stewart, G. L., Astrove, S. L., Reeves, C. J., Crawford, E. R., \& Solimeo, S. L. (2017). Those with the Most Find It Hardest to Share: Exploring Leader Resistance to the Implementation of TeamBased Empowerment. Academy of Management Journal, 60 (6), 2266-2293.

Strauch, A. (1995). Biblical Eldership: An Urgent Call to Restore Biblical Church Leadership. Colorado Springs, Colorado: Lewis \& Roth Publishers.

Supovitz, J., A., \& Tognatta, N. (2013). The impact of distributed leadership on collaborative team decision making. Leadership \& Policy in Schools, 12 (2), 101-121.

Taylor, G. (2013). Implementing and maintaining a knowledge sharing culture via knowledge management teams: A shared leadership approach. Journal of Organizational Culture, Communications \& Conflict, 17 (1), 69-91.

Timperley, H. (2005). Distributed leadership: developing theory from practice. Journal of Curriculum Studies, 37 (4), 395-420.

Tzabbar, D., \& Vestal, A. (2015). Bridging the social chasm in geographically distributed R\&D teams: The moderating effects of relational strength and status asymmetry on the novelty of team innovation. Organization Science, 26 (3), 811-829.

Van Bunderen, L., Greer, L. L., \& van Knippenberg, D. (2018). When Interteam Conflict Spirals into Intrateam Power Struggles: The Pivotal Role of Team Power Structures. Academy of Management Journal, 61 (3), 1100-1130.

Wang, D., Waldman, D., A., \& Zhen, Z. (2014). A meta-analysis of shared leadership and team effectiveness. Journal of Applied Psychology, 99 (2), 181-198.

Williamson, R., \& Blackburn, B. (2019). Collaborating Through Shared Decision-Making. Education Digest, 84 (8), 21-25.

Wood, M., S., \& Fields, D. (2007). Exploring the impact of shared leadership on management team member outcomes. Baltic Journal of Management, 2 (3), 251-272.

Woods, A., M., \& Weasmer, J. (2002). Maintaining job satisfaction: Engaging professionals as active participants. Clearing House, 75 (4), 186-189. 